Wright State University

CORE Scholar

Physics Faculty Publications

Physics

1990

\title{
A Signature of Auroral Precipitation in the Nightside lonosphere of Venus
}

Jane L. Fox

H. A. Taylor Jr.

Follow this and additional works at: https://corescholar.libraries.wright.edu/physics

Part of the Physics Commons

\section{Repository Citation}

Fox, J. L., \& Taylor, H. A. (1990). A Signature of Auroral Precipitation in the Nightside lonosphere of Venus. Geophysical Research Letters, 17 (10), 1625-1628.

https://corescholar.libraries.wright.edu/physics/327

This Article is brought to you for free and open access by the Physics at CORE Scholar. It has been accepted for inclusion in Physics Faculty Publications by an authorized administrator of CORE Scholar. For more information, please contact library-corescholar@wright.edu. 


\title{
A SIGNATURE OF AURORAL PRECIPITATION IN THE NIGHTSIDE IONOSPHERE OF VENUS
}

\author{
J. L. Fox \\ Institute for Terrestrial and Planetary Atmospheres \\ State University of New York at Stony Brook
}

\section{H. A. Taylor, Jr.}

Taylor Enterprises, Beaver River, Nova Scotia

Abstract. We show here that the densities of mass28 ions measured by the Pioneer Venus Orbiter ion mass spectrometer (OIMS) on the nightside of Venus are highly variable and show little correlation with the values of the $\mathrm{O}^{+}$densities. We have determined the total production rates of mass-28 ions in the chemical equilibrium region and find that this production rate cannot be explained by known chemical production reactions. We propose that the "excess" production is due to precipitation of electrons into the nightside thermosphere.

\section{Introduction}

The source of the Venus nightside ionosphere has been disputed since the first radio occultation measurements of the nightside electron density profile by Mariner 5 [Kliore et al., 1967]. Since then, the viable mechanisms have been reduced to two: transport of atomic ions, mostly $\mathrm{O}^{+}$, from the dayside and precipitation of energetic electrons that have been observed in the Venus umbra. Models appropriate to high solar activity have shown that plasma transport is the dominant maintenance mechanism, since it alone can produce the observed densities of $\mathrm{O}^{+}$, with electron precipitation playing a possible secondary role in enhancing the lower $\mathrm{O}_{2}^{+}$peak [Spenner et al., 1981; Cravens et al., 1983]. Gringauz et al. [1977] maintain that precipitation of electrons alone is sufficient to produce the main ion peak, as measured by the Venera 9 and 10 radio occultation experiments at solar minimum.

We have been investigating the chemistry of the nightside ionosphere, with a view toward elucidating the relative roles of electron precipitation and plasma transport in its maintenance. Model calculations based on ion transport as the source of the nightside ionosphere showed that the reaction

$$
\mathrm{O}_{2}^{+}+\mathrm{N} \rightarrow \mathrm{NO}^{+}+\mathrm{O}
$$

was the major source of $\mathrm{NO}^{+}$in the chemical equilibrium region. Analysis of data from eight Pioneer Venus (PV) orbits chosen for low periapsis and the availability of data showed that the $\mathrm{NO}^{+}$densities could be modeled with reaction (1) as the sole source for some orbits, but for others it was completely inadequate. A close look at those orbits showed that they were all characterized by high densities of mass-28 ions $\left(\mathrm{N}_{2}^{+}+\mathrm{CO}^{+}\right)$. This deviation is easily ex-

Copyright 1990 by the American Geophysical Union.

Paper number 90GLO145B

0094-8276/90/90GL-01458\$03.00 plained since $\mathrm{N}_{2}^{+}$reacts rapidly with $\mathrm{O}$ to produce $\mathrm{NO}^{+}$

$$
\mathrm{N}_{2}^{+}+\mathrm{O} \rightarrow \mathrm{NO}^{+}+\mathrm{N} \text {. }
$$

Because of the high ionization potentials of both $\mathrm{N}_{2}$ and $\mathrm{CO}$, the chemical sources are limited. Yet a survey of early Pioneer Venus orbits with periapsis below $165 \mathrm{~km}$ reveals a large variability in the maximum densities of mass-28 ions with values ranging from about $10 \mathrm{~cm}^{-3}$ to about $10^{4} \mathrm{~cm}^{-3}$. Taylor et al. [1982] had earlier remarked that the occasional large densities of $\mathrm{NO}^{+}$and $\mathrm{O}_{2}^{+}$measured by the ONMS appeared to require a source in addition to ion transport; they suggested that the densities were enhanced by particle precipitation, but the mechanism of the source was not resolved. We propose that the excess $\mathrm{NO}^{+}$is produced from $\mathrm{N}_{2}^{+}$created by particle precipitation, and that high densities of mass-28 ions in the nightside ionosphere are an in situ signature of precipitation of electrons into the nightside atmosphere.

In the discussion that follows, we identify the sources and sinks of mass-28 ions in the chemical equilibrium region, that below approximately $165-170 \mathrm{~km}$. There the ion production and loss rates are equal, so the magnitude of the source can be estimated because the total loss rate can be computed fairly accurately. From the loss rate and the known chemical sources, the "excess" production rate, that we ascribe here to particle precipitation, is determined.

\section{Sources of $\mathrm{N}_{2}^{+}$and $\mathrm{CO}^{+}$}

Reactions, references and rate coefficients used in this work are summarized in Table 1 , and the reactions numbers cited below refer to the numbers in that table. Because of the high ionization potential of $\mathrm{N}_{2}(15.58 \mathrm{eV})$, only a few charge transfer reactions of atmospheric species are energetically capable of producing $\mathrm{N}_{2}^{+}$, including charge transfer from $\mathrm{He}^{+}, \mathrm{O}^{++}$and $\mathrm{O}^{+}\left({ }^{2} D\right)$ (reactions $3-$ 5). Reaction (3) is potentially important, since nighttime $\mathrm{He}^{+}$densities are larger than daytime values, peaking in the the pre-dawn sector [Taylor et al., 1980]. Densities of $\mathrm{O}^{++}$were measured by the PV OIMS, but are often above the noise level of the instrument only above the chemical equilibrium region. In addition, the products of reaction (4) are unknown; the large exothermicity suggests that the dissociative channel probably dominates. Charge transfer from $\mathrm{O}^{+}\left({ }^{2} D\right)$ to $\mathrm{N}_{2}$, reaction (5), is a major source of $\mathrm{N}_{2}^{+}$in the dayside ionosphere [Fox, 1982], and the importance of this reaction depends on whether the metastable $\mathrm{O}^{+}\left({ }^{2} D\right)$ ian could survive transport from the dayside. A detailed analysis would be required to model the role of reaction (5) in producing the observed 
Table 1. Rate coefficients for reactions involved in the chemistry of $\mathrm{N}_{2}^{+}$and $\mathrm{CO}^{+}$in the Venus nightside ionosphere.

\begin{tabular}{llll}
\hline No. & Reaction & Rate Coefficient $\left(\mathrm{cm}^{3} \mathrm{~s}^{-1}\right)$ & References \\
\hline$(2)$ & $\mathrm{N}_{2}^{+}+\mathrm{O} \rightarrow \mathrm{NO}^{+}+\mathrm{N}$ & $1.4(-10)^{a}\left(300 / T_{i}\right)^{0.44}$ & McFarland et al. (1974) \\
$(3)$ & $\mathrm{He}^{+}+\mathrm{N}_{2} \rightarrow \mathrm{N}_{2}^{+}+\mathrm{He}$ & $4.1(-10)$ & Anicich et al. (1977) \\
$(4)$ & $\mathrm{O}^{++}+\mathrm{N}_{2} \rightarrow \mathrm{N}_{2}^{+}+\mathrm{O}^{+}$ & $\leq 1.6(-9)^{b}$ & Howorka et al. (1979) \\
$(5)$ & $\mathrm{O}^{+}\left({ }^{2} \mathrm{D}\right)+\mathrm{N}_{2} \rightarrow \mathrm{N}_{2}^{+}+\mathrm{O}$ & $8(-10)$ & Johnsen and Biondi (1980) \\
$(6)$ & $\mathrm{He}^{+}+\mathrm{CO}_{2} \rightarrow \mathrm{He}+\mathrm{CO}^{+}+\mathrm{O}$ & $7.9(-10)$ & Adams and Smith (1976); Rakshit et al. (1978) \\
$(7)$ & $\mathrm{O}^{++}+\mathrm{CO}_{2} \rightarrow \mathrm{CO}^{+}+\mathrm{O}^{+}+\mathrm{O}$ & $\leq 2(-9)^{b}$ & Johnsen and Biondi \\
$(8)$ & $\mathrm{O}^{++}+\mathrm{CO}^{\mathrm{c}} \rightarrow \mathrm{CO}^{+}+\mathrm{O}^{+}$ & $\leq 1.6(-9)^{b}$ & (assumed the same as for reaction 5) \\
$(9)$ & $\mathrm{C}^{+}+\mathrm{CO}_{2} \rightarrow \mathrm{CO}^{+}+\mathrm{CO}$ & $1.1(-9)$ & Fahey et al. (1981) \\
$(10)$ & $\mathrm{N}^{+}+\mathrm{CO}_{2} \rightarrow \mathrm{CO}^{+}+\mathrm{NO}$ & $2.5(-10)$ & Smith et al. (1978) \\
$(11)$ & $\mathrm{N}^{+}+\mathrm{CO} \rightarrow \mathrm{CO}^{+}+\mathrm{N}$ & $5.9(-10)$ & Miller et al. (1984) \\
$(12)$ & $\mathrm{CO}^{+}+\mathrm{O} \rightarrow \mathrm{CO}^{+} \mathrm{O}^{+}$ & $1.4(-10)$ & Fehsenfeld and Ferguson (1972) \\
$(13)$ & $\mathrm{N}_{2}^{+}+\mathrm{CO}_{2} \rightarrow \mathrm{N}_{2}+\mathrm{CO}_{2}^{+}$ & $7.7(-10)$ & Smith et al. (1978) \\
$(14)$ & $\mathrm{CO}^{+}+\mathrm{CO}_{2} \rightarrow \mathrm{CO}_{2}^{+}+\mathrm{CO}$ & $1(-9)$ & Adams et al. (1978) \\
$(15)$ & $\mathrm{N}_{2}^{+}+\mathrm{e} \rightarrow \mathrm{N}+\mathrm{N}$ & $2.2(-7)\left(300 / T_{e}\right)^{0.39}$ & Zipf (1980) \\
$(16)$ & $\mathrm{CO}^{+}+\mathrm{e} \rightarrow \mathrm{C}+\mathrm{O}$ & $2(-7)\left(300 / T_{e}\right)^{0.48}$ & Mitchell and Hus (1985) \\
\hline
\end{tabular}

a. Read $1.4 \times 10^{-10}$

b. The products in the reactions of $\mathrm{O}^{++}$are unknown, so the rate coefficients are upper limits only.

c. Private communication to Fox and Victor (1981).

$\mathrm{N}_{2}^{+}$, but we will show below that it can be ruled out on morphological grounds.

$\mathrm{CO}$ also has a fairly high ionization potential of 14.01 $\mathrm{eV}$. $\mathrm{CO}^{+}$can be produced by the dissociative charge transfer reaction of $\mathrm{He}^{+}$with $\mathrm{CO}_{2}$ (reaction 6) with a yield of about $79 \%$. The reaction of $\mathrm{He}^{+}$with $\mathrm{CO}$ produces very little $\mathrm{CO}^{+}$, resulting almost completely in dissociative ionization [Rakshit et al., 1978]. Production of $\mathrm{CO}^{+}$in the reaction of $\mathrm{O}^{++}$with $\mathrm{CO}_{2}$ and with $\mathrm{CO}$ (reactions 7 and 8 ) is energetically feasible, but the products in these reactions are unknown. Other possible production mechanisms are reactions of $\mathrm{C}^{+}$and $\mathrm{N}^{+}$with $\mathrm{CO}_{2}$ and $\mathrm{CO}$ (reactions 9-11). These reactions are potentially important, since $\mathrm{C}^{+}$and $\mathrm{N}^{+}$should be transported from the dayside along with $\mathrm{O}^{+}$, although with much smaller fluxes.

If chemical sources are insufficient to produce the observed mass-28 ion densities, only particle impact, especially electron impact, on $\mathrm{N}_{2}, \mathrm{CO}$ and $\mathrm{CO}_{2}$ remains a viable mechanism. The source due to chemical reactions can be computed if the densities of the species involved are measured. The OIMS measured densities of $\mathrm{He}^{+}$, $\mathrm{O}^{++}, \mathrm{C}^{+}$, and $\mathrm{N}^{+}$, but values are not available for all of the rightside passes of the PVO, nor at all altitudes. Nonetheless, it is possible to compute the source of mass28 ions due to reactions (3-11) for a number of orbits over some part of the chemical equilibrium region.

\section{Total Production Rate of Mass-28 Ions}

Since both $\mathrm{N}_{2}^{+}$and $\mathrm{CO}^{+}$contribute to the measured density, it is not possible to compute the total loss rate exactly. Fortunately, however, the rate coefficients for the major reactions of $\mathrm{CO}^{+}$and $\mathrm{N}_{2}^{+}$are nearly equal, so an approximate value for the total loss rate can be obtained. The most important loss mechanism for both ions is reaction with $O$ (reactions 2 and 12). The rate coefficients for both reactions (2) and (12) are close to $1.4 \times 10^{-10} \mathrm{~cm}^{3} \mathrm{~s}^{-1} . \mathrm{N}_{2}^{+}$and $\mathrm{CO}^{+}$also react at nearly gas kinetic rates with $\mathrm{CO}_{2}$ (reactions 13 and 14). Dissociative recombination (reactions 15 and 16 ) is the major loss mechanism for both ions at high altitudes. Rate coeffcients of $2.2 \times 10^{-7}$ and $2.0 \times 10^{-7} \mathrm{~cm}^{3} \mathrm{~s}^{-1}$ at $300 \mathrm{~K}$ have been reported for $\mathrm{N}_{2}^{+}$and $\mathrm{CO}^{+}$, respectively. To approx- imate the total loss rate of mass-28 ions we used averaged values for the rate coefficients. Errors of less than $15 \%$ or so, substantially less than the uncertainty in the rate coefficients themselves, result from this assumption.

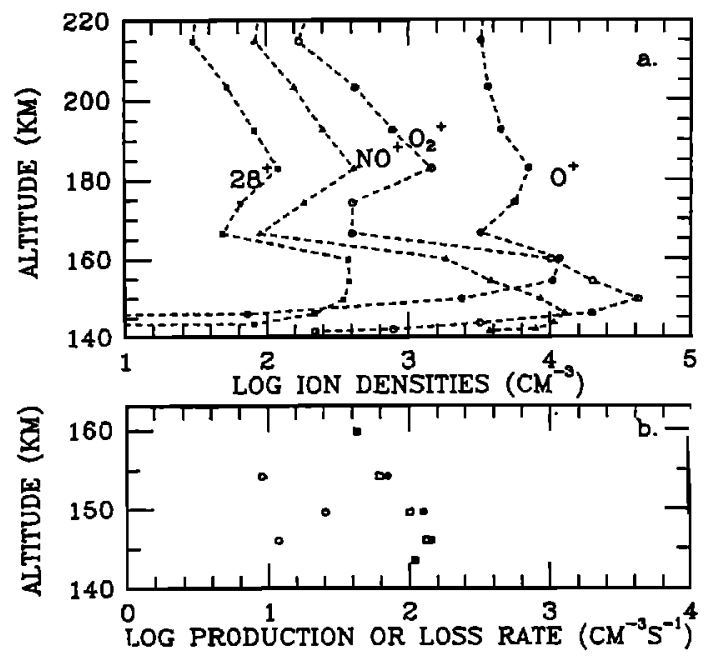

Fig. 1a. Densities of major ions for orbit 505 (inbound) from PV orbiter ion mass spectrometer data. 1b. Total production rate of mass-28 ions (filled circles), production rate due to chemical reactions (open circles) and excess production (open squares), for Orbit 505 (inbound).

Figures 1a and $2 \mathrm{a}$ show the major ion densities for orbits 505 and 529. Periapses for orbits 505 and 529 were at 22.1 and 0.7 hours local time and solar zenith angles of $149.5^{\circ}$ and $163.2^{\circ}$, respectively, so both orbits were near the antisolar point. The maximum mass-28 ion density is a factor of more than 25 larger for orbit 529 than orbit 505. Figures $1 b$ and $2 b$ compare the total loss rates of mass-28 ions (reactions 2 and 12-16) to the production rates due to reactions (3-11) in the chemical equilibrium region for the two orbits. The maximum mass-28 ion loss rate for orbit 529 is about $10^{4} \mathrm{~cm}^{-3} \mathrm{~s}^{-1}$, whereas the production rate due to chemical reactions is only $10-20$ $\mathrm{cm}^{-3} \mathrm{~s}^{-1}$. The excess praduction is on the order of $10^{4}$ 


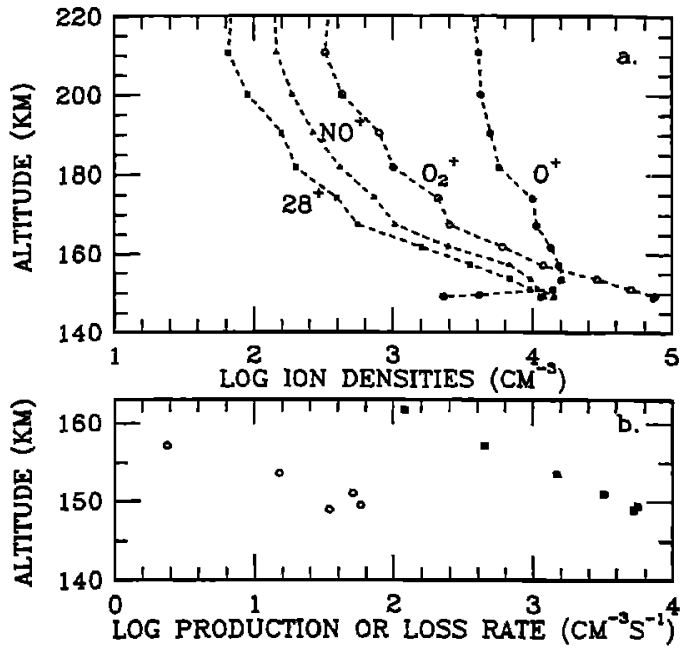

Fig. 2. Same as for Fig. 1, but for Orbit 529 (inbound). In Fig. 2b, the total production rate and excess production rate are essentially superimposed.

$\mathrm{cm}^{-3} \mathrm{~s}^{-1}$. For orbit 505 , the maximum auroral production rate is about a factor of 40 less than for orbit 529 , although the production rates due to chemical reactions are about the same for the two orbits.

Other evidence for the precipitation of electrons into the nightside thermosphere exists. Fluxes of suprathermal electrons have been measured above the atmosphere in the Venus umbra by the PV retarding potential analyzer (ORPA) [e.g. Knudsen and Miller, 1985] as well as by the plasma analyzers on the Soviet Venera 9 and 10 spacecraft [e.g. Gringauz et al., 1977]. Continuous but highly variable emissions of atomic oxygen at 1304 and $1356 \AA$ have been observed in images of the nightside of Venus by the PV orbiter uitraviolet spectrometer (OUVS) [Phillips et al., 1986]. Fox and Stewart [1990] have proposed that these emissions are caused by the precipitation of soft electrons into the nightside atmosphere.

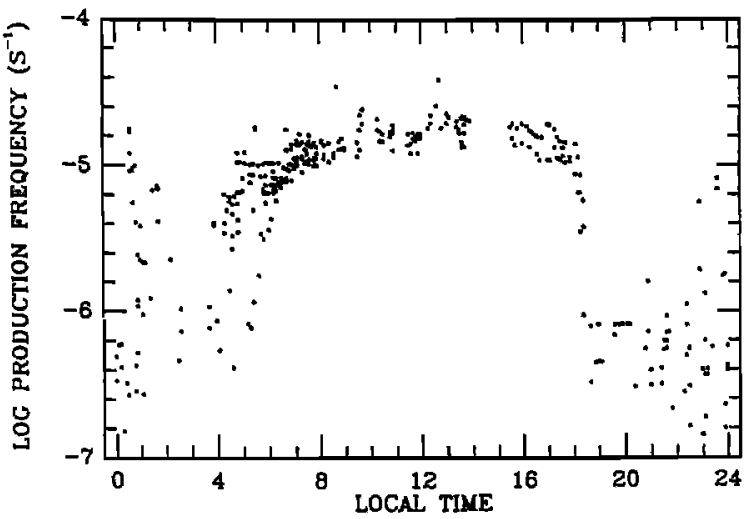

Fig. 3. Production frequency of mass-28 ions in excess of that that can be accounted for by chemical reactions at the mass-28 ion peak as a function of local time for all orbits of the first 600 for which sufficient data are available.

Figure 3 shows the excess production "frequency" of mass-28 ions at the mass-28 ion peak for all orbits among the first 600 that meet the following criteria: periapsis al- titude below $165 \mathrm{~km}$, and data at the mass-28 ion peak for the densities of $\mathrm{O}^{+}, \mathrm{O}_{2}^{+}, \mathrm{He}^{+}, \mathrm{CO}_{2}, \mathrm{O}$, and $\mathrm{N}_{2}$. In this calculation, only the reactions of $\mathrm{He}^{+}$(reactions 3 and 5 ) were included as chemical sources of mass-28 ions, since experience with individual orbits showed the other sources to be unimportant. The electron temperature was assumed to be about $1000 \mathrm{~K}$ for all the data points. Errors resulting from this assumption should be small, since the electron temperature dependence of the dissociative recombination coefficient is weak, and dissociative recombination is not the major loss mechanism. In order to reduce the effects of variability due to changes in the neutral atmosphere and in the altitude of periapsis, the excess production "frequency" was obtained by dividing the rate by the factor $3\left[\mathrm{~N}_{2}\right]+0.1\left[\mathrm{CO}_{2}\right]$. The first term in the factor represents ionization of $\mathrm{N}_{2}$ and $\mathrm{CO}$, and was chosen because the $\mathrm{CO}$ density is about twice the $\mathrm{N}_{2}$ density on the nightside above the homopause [Hedin et al., 1983]. The second term represents the contribution of dissociative ionization of $\mathrm{CO}_{2}$; the factor 0.10 is the high energy ratio of the electron impact cross sections for production of $\mathrm{CO}^{+}$from $\mathrm{CO}_{2}$ and $\mathrm{CO}$. On the dayside, the excess production is due to direct ionization and chemical reaction other than reactions (3) and (6). The production frequency appears large on the dayside also because $\mathrm{CO}$ is more abundant relative to $\mathrm{N}_{2}$ there [Hedin et al., 1983]. The variability on the dayside is small, because all the data were taken near solar maximum, but some scatter remains from the variation of periapsis altitude. The large variability in the source on the nightside, ranging over more than two orders of magnitude, itself suggests particle precipitation as the source mechanism. Some excess production appears to be present in nearly all the orbits. This is consistent with the morphology of the $1304 \AA$ aurora [Phillips et al., 1986], which is nearly always visible on the nightside, but exhibits large spatial and temporal variations.

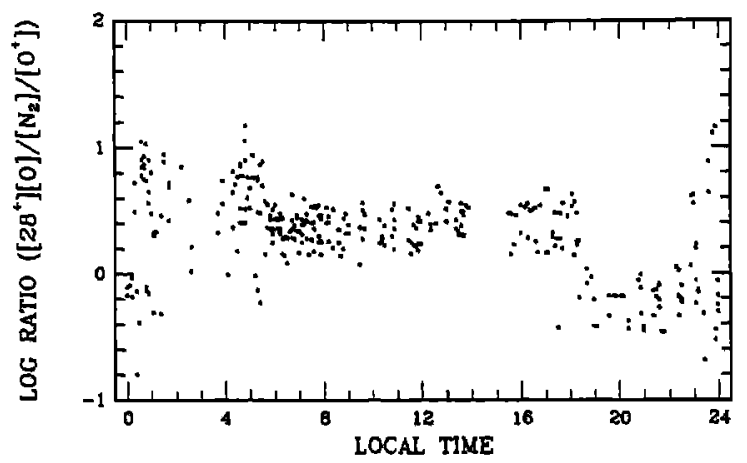

Fig. 4. Ratio of $\left[28^{+}\right][\mathrm{O}] /\left[\mathrm{N}_{2}\right]$ at the mass-28 ion peak to the density of $\mathrm{O}^{+}$at its peak, as a function of local time for the first 600 orbits. The variability on the nightside is substantially greater than the variability on the dayside.

Since models have shown that the measured $\mathrm{O}^{+}$densities can only be accounted for by transport from the dayside, and if mass-28 ions are mostly produced by auroral processes, the relative values of the maximum mass-28 ion and $\mathrm{O}^{+}$densities would be indicative of the relative importance of ion transport and particle precipitation in the nightside ionosphere. Figure 4 is a plot of the ratio of the peak mass-28 ion density (divided by $\left[\mathrm{N}_{2}\right] /[\mathrm{O}]$ ) to the peak $\mathrm{O}^{+}$density as a function of local time for all orbits 
with periapsis below $165 \mathrm{~km}$ and with available mass-28 ion, $\mathrm{O}^{+}, \mathrm{N}_{2}$ and $\mathrm{O}$ densities. Here the factor $\left[\mathrm{N}_{2}\right] /[\mathrm{O}]$ is chosen to limit the scatter due to the variability of the neutral atmosphere and the change in the altitude of periapsis. The remaining large orbit to orbit variability is itself indicative of particle precipitation as the source of the mass-28 ion. The occurrence of very high values is of particular interest, as it shows that sufficient electron precipitation is present, at least occasionally, to affect the ion densities substantially. The large variation in the ratio also shows that high mass-28 ion densities are not correlated with high $\mathrm{O}^{+}$densities and that transport of $\mathrm{O}^{+}\left({ }^{2} \mathrm{D}\right)$ is unlikely as a source of mass-28 ions, since the transport of the metastable ion would be expected to be correlated with the transport of $\mathrm{O}^{+}$.

\section{Conclusions}

We have shown that the total production rate of mass28 ions in the Venus nightside ionosphere cannot be accounted for by chemical production resulting from transport of atomic ions from the dayside for a substantial number of orbits of the Pioneer Venus spacecraft. We ascribe the missing production to precipitation of particles, possibly the same electrons that are implicated in the production of the ultraviolet "auroral" emissions. A study of the production rate at the mass- 28 ion density maximum for all orbits of the first 600 for which sufficient data are available shows that the auroral production rate is highly variable, with maximum values of about $10^{4}$ $\mathrm{cm}^{-3} \mathrm{~s}^{-1}$. This great variability points to particle precipitation as the source.

Acknowledgments. JLF thanks NASA Goddard Space Flight Center for their hospitality and aid in accessing the UADS data base. This work has been supported in part by NASA grants NAGW-665 and NAG2-523 to the State University of New York.

\section{References}

Adams, N. G. and D. Smith, Product ion distributions for some ion-molecule reactions, J. Phys. B., g, 1439, 1976.

Adams, N. G., D. Smith and D. Grief, Reactions of $\mathrm{H}_{\mathrm{n}} \mathrm{CO}^{+}$with molecules at $300 \mathrm{~K}$, Int. J. Mass Spectr. Ion Phys., 26, 405, 1978.

Anicich, V. G., J. B. Laudenslager, W. T. Huntress, and J. H. Futrell, J. Chem. Phys 67, 4340, 1977.

Cravens, T. E., S. L. Crawford, A. F. Nagy and T. I. Gombosi, A two-dimensional model of the ionosphere of Venus, J. Geophys. Res. 88, 5595, 1983.

Fahey, D. W., F. C. Fehsenfeld, and E. E. Ferguson, Rate constant for the reaction $\mathrm{C}^{+}+\mathrm{CO}_{2}$ at collision energies 0.04 to $2.5 \mathrm{eV}$, Geophys. Res. Lett, 8, 1115, 1981.

Fehsenfeld, F. C., and E. E. Ferguson, Thermal energy reaction rate constants for $\mathrm{H}^{+}$and $\mathrm{CO}^{+}$with $\mathrm{O}$ and NO, J. Chem. Phys, 56, 3066, 1972.

Fox, J. L., The chemistry of metastable species in the Venusian ionosphere, Icarus, 51, 248, 1982.

Fox, J. L. and A. I. F. Stewart, The Venus ultraviolet aurora: a soft electron source, submitted to J. Geophys. Res., 1990.
Fox, J. L. and G. A. Victor, $\mathrm{O}^{++}$in the Venusian ionosphere, J. Geophys. Res., 86, 2438, 1981.

Gringauz, K. I., M. I. Verigin, T. K. Breus and T. Gombosi, Electron currents measured in the optical shadow of Venus by the Venera-9 and Venera-10 satellites, Sov. Phys. Dokl., 22, 53, 1977.

Hedin, A. E., H. B. Niemann, W. T. Kasprzak, and A. Seiff, Global empirical model of the Venus thermosphere, J. Geophys. Res., 88, 73, 1983.

Howorka, F., et al., Laboratory studies of $\mathrm{O}^{++}$reactions of ionospheric importance, J. Geophys. Res., $84,5941,1979$.

Kliore, A., et al., Atmosphere and ionosphere of Venus from the Mariner V S-band radio occultation measurement, Science, 158, 1683, 1967.

Knudsen, W. C. and K. L. Miller, Pioneer Venus superthermal electron flux measurements in the Venus umbra, J. Geophys. Res., 90, 2695, 1985.

McFarland, M., et al., A flow-drift technique for ion mobility and ion-molecule rate constant measurements, J. Chem. Phys., 59, 6620, 1974.

Miller, T. M., R. E. Wetterskog, and J. F. Paulson, Temperature dependence of the ion-molecule reactions $\mathrm{N}^{+}+\mathrm{CO}, \mathrm{C}^{+}+\mathrm{NO}$, and $\mathrm{C}^{+}, \mathrm{CO}^{+}, \mathrm{CO}_{2}^{+}+\mathrm{O}_{2}$ from $90-450 K$, J. Chem. Phys, 80, 4922, 1984.

Mitchell, J. B. A. and H. Hus, The dissociative recombination and excitation of $\mathrm{CO}^{+}, J$. Phys. B., 18, 546, 1985.

Phillips, J. L., A. I. F. Stewart, and J. G. Luhmann, The Venus ultraviolet aurora: observations at $130.4 \mathrm{~nm}$, Geophys. Res. Lett. 13, 1047, 1986.

Rakshit, A. B., H. M. P. Stock, D. P. Wareing, and N. D. Twiddy, Some ion-molecule reaction rate coefficient measurements at 300 and $100 \mathrm{~K}$ in a temperaturevariable flowing afterglow apparatus, J. Phys. B., $11,4237,1978$.

Smith, D., N. G. Adams, and T. M. Miller, A laboratory study of the reactions of $\mathrm{N}^{+}, \mathrm{N}_{2}^{+}, \mathrm{N}_{3}^{+}, \mathrm{N}_{4}^{+}, \mathrm{O}^{+}, \mathrm{O}_{2}^{+}$, and $\mathrm{NO}^{+}$ions with several molecules at $300 \mathrm{~K}, J$. Chem. Phys, 69, 308, 1978.

Spenner, K., et al., On the maintenance of the Venus nightside ionosphere: electron precipitation and plasma transport, J. Geophys. Res., 86, 9170, 1981.

Taylor, H. A., Jr., et al., Global observations of the composition and dynamics of the ionosphere of Venus: Implications for solar wind interaction, $J$. Geophys. Res., 85, 7765, 1980.

Taylor, H. A., Jr., et al., Observed composition of the ionosphere of Venus: implications for the ionization peak and the maintenance of the nightside ionosphere, Icarus, 51, 283, 1982.

Zipf, E. C., The dissociative recombination of vibrationally excited $\mathrm{N}_{2}^{+}$ions, Geophys. Res. Lett., 7, 645, 1980 .

J. L. Fox, Department of Mechanical Engineering, State University of New York, Stony Brook, NY 11794.

H. A. Taylor, Jr., Taylor Enterprises, R. R. 1, Box 2495, Beaver River, Nova Scotia B5A 4A5, Canada.

(Received June 4, 1990; accepted June 19, 1990.) 